\title{
Nigerian Journal of Technology
}

\section{VOLUME 35, NUMBER 4, OCTOBER 2016}

... publishing original technical and scholarly reports since 1975

www.nijotech.com

nijo.tech@unn.edu.ng 


\section{INDEXING BODIES}

CrossRef®,

ProQuest ${ }^{\circledR}$

EBSCO Host ${ }^{\circledR}$,

Scholar Google ${ }^{\circledR}$,

African Journal Online (AJOL) ®

Directory of Open Access Journals (DOAJ) ${ }^{\circledR}$ 